\title{
Mixed Convection Characteristics of Ethylene Glycol and Water Mixture Based $\mathrm{Al}_{2} \mathrm{O}_{3}$ Nanofluids
}

\author{
Elif Büyük Öğ̈̈̈t ${ }^{1}$, Kamil Kahveci $^{2}$ \\ ${ }^{1}$ Vocational School of Gebze, Kocaeli University, 41800 Hereke-Kocaeli / Turkey \\ elif.ogut@kocaeli.edu.tr \\ ${ }^{2}$ Mechanical Engineering Department, Trakya University, 22180 Edirne / Turkey \\ kamilk@trakya.edu.tr
}

\begin{abstract}
Mixed convection of ethylene glycol (EG) and water mixture based $\mathrm{Al}_{2} \mathrm{O}_{3}$ nanofluids in a lid-driven square enclosure heated from the left wall and cooled from the top wall was investigated numerically in this study. The Grashof number was kept at a constant value of $10^{4}$. Reynolds number was assumed to vary in a range so that the Richardson number gets values in the range of 0.1 to 10 . Three different nanoparticle volume fractions were considered: $0 \%, 4 \%$ and $8 \%$. Six different volume ratios of EG to water were taken into consideration, 0:100 \%, 20:80 \%, 40:60\%, 60:40\%, 80:20\% and 100:0\%. The results show that an increase in the average Nusselt number is seen with an increase in the volume fraction of nanoparticles and with a decrease in the Richardson number. The results also show that average Nuselt number shows a considerable increase with an increase of EG volume fraction in the base fluid.
\end{abstract}

Keywords: Mixed convection, square enclosure, nanofluid, water, ethylene glycol.

\section{Introduction}

Conventional heat transfer fluids such as water, oil and ethylene glycol has a low thermal conductivity. This is the primary limitation in enhancing the performance and compactness of many electronic devices in engineering. To improve the thermal conductivitiy of a fluid solid particles in nano size are added into a base fluid. The resulting mixture, referred to as a nanofluid, has a considerably higher thermal conductivity than that of the base fluid [1]. Anomalous increase in thermal conductivity can be attributed to the four factors: Brownian motion, molecular-level layering of the liquid, the nature of heat transfer mechanism and the nanoparticle clustering [2].

There are a considerable number of studies in the literature on natural and forced convective heat transfer of nanofluids [3-7] .On the other hand, studies on mixed convection heat transfer are relatively limited. In one of these studies, Akbarinia and Behzadmehr [8] conducted a numerical study on fully developed laminar mixed convection of a nanofluid in a horizontal curved tube. Their results show that, for a given Reynold number, buoyancy force has a negative effect on the Nusselt number while the nanoparticles concentration has a positive effect on heat transfer enhancement and also on skin friction reduction. Kahveci and Ogut [9] studied mixed convection of water-based nanofluids in a lid-driven square enclosure with a constant heat flux heater. The results show that the heat transfer rate increases considerably with a decrease in the Richardson number and length of the heater. Kalteh et al. [10] made a numerical investigation on laminar mixed convection flow of water-based nanofluids in a lid-driven square cavity with a triangular heat source. The results show that increasing the nanoparticles diameter leads to a decrease in the average Nusselt number for all Richardson numbers. The results also show that the average Nusselt number increases by a decrease in the heat source height. Kefayati [11] studied mixed convection of non- Newtonian nanofluids in a lid-driven enclosure with sinusoidal temperature profile. The results indicate that the effect of nanoparticles on the enhancement of heat transfer decreases with an increase in the power-law index. Garoosi and Hoseininejad [12] conducted a numerical study on natural and mixed convection heat transfer between differentially heated cylinders in an adiabatic enclosure filled with nanofluid. Their results indicate that heat transfer rate may increase or decrease by changing rotation direction of the hot and cold cylinders, and it is found that, by changing the location of the heat source/sink from bottom-top to top-bottom configuration, heat transfer rate decreases significantly. Their results also show that average Nusselt number reduces dramatically by a change of the position of the cold cylinder from vertical to horizontal mode. Ahmet et al. [13] numerically investigated mixed convection from a discrete heat source in enclosures with two adjacent moving walls and filled with nanofluids. Their results show that both the Richardson number and moving lid ordinations have a 
significant effect on the flow and thermal fields in the enclosure. Hasib et al. [14] studied the effect of tilt angle on mixed convection flow in trapezoidal cavities filled with water- $\mathrm{Al}_{2} \mathrm{O}_{3}$ nanofluid. Their results show that tilting the enclosure increases heat transfer from heated wall for short based trapezoids, while it decreases for long based trapezoid.

Water, ethylene glycol or propylene glycol are usually used as single base fluids in a base fluid-nanofluid- mixture. On the other hand, the use of water + glycol mixtures as base fluid combines the advantages of both pure compounds, since mixtures exhibit higher thermal conductivity than their pure glycols and a lower freezing point than water [15]. Therefore, glycoled water is used in a large number of practical applications such as antifreeze in car engines or transfer medium in solar heating installations $[16,17]$. Accordingly, mixed convection of EG/ water mixture based $\mathrm{Al}_{2} \mathrm{O}_{3}$ nanofluids in a liddriven square enclosure heated from one side and cooled from the stationary adjacent side wall was investigated numerically in this study to reveal the effects of governing parameters on the heat transfer and fluid flow.

\section{Analysis}

The geometry and the coordinate system used in the analysis are seen in Fig. 1. Nanofluid inside the enclosure was assumed to be heated and cooled by the left and top walls at uniform temperatures of $\mathrm{T}_{\mathrm{H}}$ and $\mathrm{T}_{\mathrm{C}}$, respectively. The right and bottom walls of the enclosure were assumed to be adiabatic. The hot vertical wall was also assumed to move in positive y direction with a constant velocity. The nanofluid in the enclosure was assumed to be Newtonian and incompressible, and flow was assumed laminar. It was also assumed that both the fluid particles and nanoparticles are in a thermal equilibrium and they flow at the same velocity. The thermos-physical properties of the nanofluid were assumed constant except for the density in the buoyancy force term. The viscous dissipation terms and the thermal radiation were also assumed to be negligible.

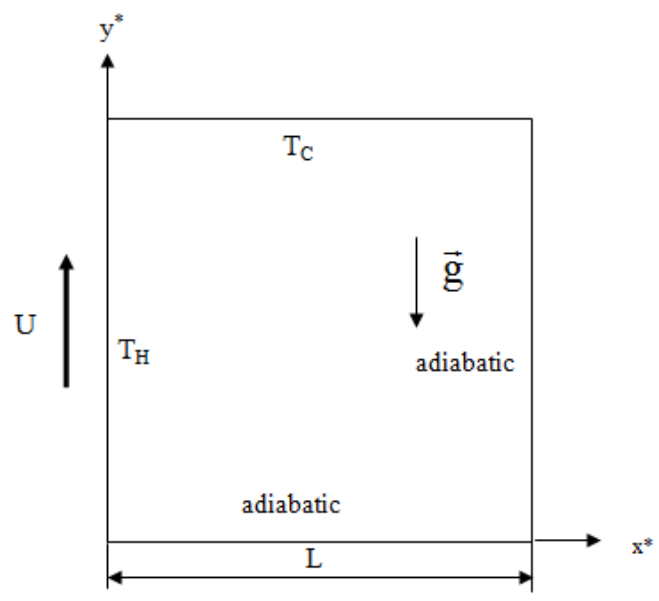

Fig. 1: Geometry and the coordinate system.

In order to nondimensionalize the governing equations, following dimensionless variables were used:

$$
\begin{gathered}
\mathrm{x}=\frac{\mathrm{x}^{*}}{\mathrm{~L}}, \quad \mathrm{y}=\frac{\mathrm{y}^{*}}{\mathrm{~L}}, \\
\mathrm{u}=\frac{\mathrm{u}^{*}}{\mathrm{U}}, \mathrm{v}=\frac{\mathrm{v}^{*}}{\mathrm{U}}, \mathrm{p}=\frac{\mathrm{p}^{*}}{\rho_{\mathrm{f}, 0} \mathrm{U}^{2}}, \quad \theta=\frac{\mathrm{T}-\mathrm{T}_{\mathrm{C}}}{\mathrm{T}_{\mathrm{H}}-\mathrm{T}_{\mathrm{C}}}
\end{gathered}
$$

where $\mathrm{g}$ is gravitational acceleration, $\mathrm{L}$ is the dimensional length of the square enclosure, $\mathrm{U}$ is the velocity of the hot vertical wall, $\mathrm{u}^{*}$ and $\mathrm{v}^{*}$ are the dimensional velocities in the $\mathrm{x}^{*}$ and $\mathrm{y}^{*}$ directions, respectively, $\mathrm{p}^{*}$ is the dimensional pressure, $\rho_{\mathrm{f}, 0}$ is the density of the fluid at temperature $\mathrm{T}_{\mathrm{C}}$ and $\theta$ is the nondimensional temperature. With these dimensionless variables, nondimensional governing equations in vorticity-stream function formulation take the following form:

Stream function equation: 


$$
-\omega=\frac{\partial^{2} \psi}{\partial x^{2}}+\frac{\partial^{2} \psi}{\partial y^{2}}
$$

Vorticity transport equation:

$$
\mathrm{u} \frac{\partial \omega}{\partial \mathrm{x}}+\mathrm{v} \frac{\partial \omega}{\partial \mathrm{y}}=\frac{\rho_{\mathrm{f}}}{\rho_{\mathrm{nf}, \mathrm{o}}} \frac{1}{\operatorname{Re}} \frac{\mu_{\mathrm{nf}}}{\mu_{\mathrm{f}}}\left(\frac{\partial^{2} \omega}{\partial \mathrm{x}^{2}}+\frac{\partial^{2} \omega}{\partial \mathrm{y}^{2}}\right)+\frac{(1-\phi) \rho_{\mathrm{f}} \beta_{\mathrm{f}}+\phi \rho_{\mathrm{s}} \beta_{\mathrm{s}}}{\beta_{\mathrm{f}} \rho_{\mathrm{nf}, \mathrm{o}}} \frac{\mathrm{Gr}}{\operatorname{Re}^{2}}\left(\frac{\partial \theta}{\partial \mathrm{x}}\right)
$$

Energy equation:

$$
\mathrm{u} \frac{\partial \theta}{\partial \mathrm{x}}+\mathrm{v} \frac{\partial \theta}{\partial \mathrm{y}}=\frac{\alpha_{\mathrm{nf}}}{\alpha_{\mathrm{f}}} \frac{1}{\operatorname{Re} \operatorname{Pr}}\left(\frac{\partial^{2} \theta}{\partial \mathrm{x}^{2}}+\frac{\partial^{2} \theta}{\partial \mathrm{y}^{2}}\right)
$$

where $\alpha_{n f}=\frac{k_{n f}}{\left(\rho c_{p}\right)_{n f, 0}}$.

The Reynolds, Prandtl, and Grashof numbers in the governing equations are defined as:

$$
\operatorname{Re}=\frac{\mathrm{UL} \rho_{\mathrm{f}, 0}}{\mu_{\mathrm{f}}}, \operatorname{Pr}=\frac{\mu_{\mathrm{f}}}{\rho_{\mathrm{f}, 0} \alpha_{\mathrm{f}}}, \mathrm{Gr}=\frac{\rho_{\mathrm{f}, 0}{ }^{2} \mathrm{~g} \beta_{\mathrm{f}} \mathrm{L}^{3}\left(\mathrm{~T}_{\mathrm{H}}-\mathrm{T}_{\mathrm{C}}\right)}{\mu_{\mathrm{f}}{ }^{2}},
$$

where $\mu$ is the viscosity, $\beta$ is the thermal expansion coefficient and $\alpha$ is the thermal diffusivity of the fluid. In this study, the viscosity of the nanolfuid was assumed to be predicted by the Brinkman model [18]:

$$
\mu_{\mathrm{nf}}=\frac{\mu_{\mathrm{f}}}{(1-\phi)^{2.5}}
$$

The density, heat capacitance and Boussinesq term of nanofluid can be expressed by the following relation [19]:

$$
\begin{gathered}
\rho_{\mathrm{nf}, \mathrm{o}}=(1-\phi) \rho_{\mathrm{f}, \mathrm{o}}+\phi \rho_{\mathrm{s}, \mathrm{o}} \\
\left(\rho c_{\mathrm{p}}\right)_{\mathrm{nf}}=(1-\phi) \rho_{\mathrm{f}} \mathrm{c}_{\mathrm{p}_{\mathrm{f}}}+\phi \rho_{\mathrm{s}} \mathrm{c}_{\mathrm{ps}} \\
(\rho \beta)_{\mathrm{nf}}=(1-\phi) \rho_{\mathrm{f}} \beta_{\mathrm{f}}+\phi \rho_{\mathrm{s}} \beta_{\mathrm{s}}
\end{gathered}
$$

where, $\phi$ is the volume fraction of solid particles and subscripts $\mathrm{f}$, $\mathrm{nf}$ and s stand for base fluid, nanofluid and solid, respectively.

The Yu and Choi [20] model was used in this study for the thermal conductivity prediction of nanofluid:

$$
\frac{\mathrm{k}_{\mathrm{nf}}}{\mathrm{k}_{\mathrm{f}}}=\frac{\mathrm{k}_{\mathrm{s}}+2 \mathrm{k}_{\mathrm{f}}+2\left(\mathrm{k}_{\mathrm{s}}-\mathrm{k}_{\mathrm{f}}\right)(1+\eta)^{3} \phi}{\mathrm{k}_{\mathrm{s}}+2 \mathrm{k}_{\mathrm{f}}-\left(\mathrm{k}_{\mathrm{s}}-\mathrm{k}_{\mathrm{f}}\right)(1+\eta)^{3} \phi}
$$

where $\eta$ is the ratio of the nanolayer thickness to the original particle radius.

The governing equations are subjected to the following boundary conditions:

$$
\psi(\mathrm{x}, 0)=0, \psi(\mathrm{x}, 1)=0, \psi(0, \mathrm{y})=0, \psi(1, \mathrm{y})=0
$$




$$
\begin{gathered}
\left.\frac{\partial \psi}{\partial y}\right|_{y=0}=0,\left.\frac{\partial \psi}{\partial y}\right|_{y=1}=0,\left.\frac{\partial \psi}{\partial x}\right|_{x=0}=+1,\left.\frac{\partial \psi}{\partial x}\right|_{x=1}=0 \\
\theta(0, y)=1, \theta(x, 1)=0,\left.\frac{\partial \theta}{\partial x}\right|_{x=1}=0,\left.\frac{\partial \theta}{\partial y}\right|_{y=0}=0
\end{gathered}
$$

The boundary condition for the vorticity on the walls is expressed from the stream function equation as $\omega_{\text {wall }}=-\partial^{2} \psi / \partial \varsigma^{2}$, where $\varsigma$ is the outward direction normal to the surface.

The local Nusselt number along the hot wall of the enclosure can be defined as:

$$
\mathrm{Nu}=\frac{\mathrm{Q}}{\mathrm{Q}_{\text {cond,fluid }}}=-\frac{\left(\mathrm{k}_{\mathrm{nf}}\right)_{\text {stagnant }}}{\mathrm{k}_{\mathrm{f}}} \frac{\partial \theta}{\partial \mathrm{x}}
$$

where

$$
\mathrm{Q}=-\left.\left(\mathrm{k}_{\mathrm{nf}}\right)_{\text {stagnant }} \mathrm{A} \frac{\partial \mathrm{T}}{\partial \mathrm{x}^{*}}\right|_{\mathrm{x}^{*}=0}
$$

The average Nusselt number on the hot wall can then be defined by the following relation:

$$
\mathrm{Nu}_{\mathrm{a}}=\int_{0}^{1} \mathrm{Nudy}
$$

\section{Results and Discussion}

The thermo-physical properties of the base fluids and nanoparticle used in this study are shown in Table 1 The Grashof number was assumed constant at a value of $10^{4}$, and the Reynolds number is varied such that the Richardson number gets values in the range of 0.1-10. The Richardson number determining the ratio of the buoyancy force to the shear force is defined as $\mathrm{Ri}=\mathrm{Gr} / \mathrm{Re}^{2}$. Three different nanoparticle volume fractions were taken into consideration: $0 \%, 4 \%$ and $8 \%$ and the value of $\eta$, the ratio of the nanolayer thickness to the original particle radius, was fixed to 0.1 . The computational results were obtained for six different volume ratios of EG to water, 0:100\%, 20:80\%, 40:60\%, 60:40\%, 80:20\%, 100:0 \%. The solutions of the governing equations were obtained by Comsol Multiphysics finite element modelling and simulation software.

Table 1: Thermophysical properties.

\begin{tabular}{|l|l|l|l|l|l|l|l|}
\hline Property & $\begin{array}{l}0: 100 \% \\
\text { EG/W }\end{array}$ & $\begin{array}{l}20: 80 \% \\
\text { EG/W }\end{array}$ & $\begin{array}{l}40: 60 \% \\
\text { EG/W }\end{array}$ & $\begin{array}{l}60: 40 \% \\
\text { EG/W }\end{array}$ & $\begin{array}{l}80: 20 \% \\
\text { EG/W }\end{array}$ & $\begin{array}{l}100: 0 \% \\
\text { EG/W }\end{array}$ & $\mathrm{Al}_{2} \mathrm{O}_{3}$ \\
\hline$\rho\left(\mathrm{kg} / \mathrm{m}^{3}\right)$ & 997.1 & 1027.93 & 1057.60 & 1083.87 & 1107.40 & 1132 & 3970 \\
\hline $\mathrm{c}_{\mathrm{p}}(\mathrm{j} / \mathrm{kg} \mathrm{K})$ & 4180 & 3826 & 3485 & 3106 & 2690 & 2349 & 765 \\
\hline $\mathrm{k}(\mathrm{W} / \mathrm{m} \mathrm{K})$ & 0.613 & 0.498 & 0.408 & 0.336 & 0.283 & 0.258 & 40 \\
\hline$\mu(\mathrm{mPa} / \mathrm{s})$ & 0.891 & 1.46 & 2.57 & 4.52 & 8.29 & 15.1 & - \\
\hline$\alpha \times 10^{7}\left(\mathrm{~m}^{2} / \mathrm{s}\right)$ & 1.47 & 1.266 & 1.106 & 0.998 & 0.95 & 0.97 & 131.7 \\
\hline$\beta\left(\mathrm{K}^{-1}\right)$ & 0.00021 & 0.00028 & 0.00035 & 0.00042 & 0.00049 & 0.00057 & 0.000024 \\
\hline $\operatorname{Pr}$ & 6.07 & 11.21 & 21.95 & 41.78 & 78.79 & 137.48 & - \\
\hline
\end{tabular}

The streamlines and isotherms in the enclosure are shown in Figure 2 for pure water as base fluid. As it can be seen, flow in the enclosure is unicellular for all values of Ri number and solid volume fraction. The heated fluid particles rise along the left wall as a result of buoyancy forces and shear forces until they reach the top wall, where they turn rightward, toward the sidewalls, while they are cooled by the top wall. Then they turn downward and the restriction imposed by the bottom 
wall force them to turn leftward. The flow path is completed as the colder fluid particles are entrained to the ascending flow along the hot wall. The boundary-layer flow regime is clearly seen in the enclosure by the steepness of the isotherms near the vertical left wall and horizontal top wall. For low values of Ri number, flow is shear dominated. Therefore, an increase in the nanoparticle volume fraction does mot effect the flow field considerably. However, circulation intensity shows an increase with an increase in the nanoparticle solid volume fraction when the Ri number gets higher values. For high values of Ri number, flow is buoyancy dominant and energy transport from the hot wall to the fluid increases with an increase in the solid volume fraction as a result of higher thermal conductivity of the nanofluid. As shown in figure, the clustering of isotherms near the hot wall decreases with an increase in the solid volume fraction because of increase in the thermal diffusion.

The streamlines and isotherms in the enclosure are given in Figures 3-5 for various values of EG to water volume ratios. As it can be observed from figures that an increase in EG volume fraction has no significant effect on flow field for low values of the Richardson number. With an increase in the Richardson number circulation intensity gets lower values with an increase in the ethylene glycol volume fraction. For high values of Richardson number, flow is buoyancy dominant. An increase in the ethylene glycol ratio results in an increase in the Prandtl number. For high vales of Prandtl number, the viscous forces is dominant over the thermal forces. Therefore, circulation intensity weakens by an increase of Prandtl number for high values of Richardson number. With an increase in the EG volume ratio, therefore in Prandtl number, isotherms become more condensed near the hot wall. This is because of the fact that thermal boundary layer gets thinner with an increase in the Prandtl number.

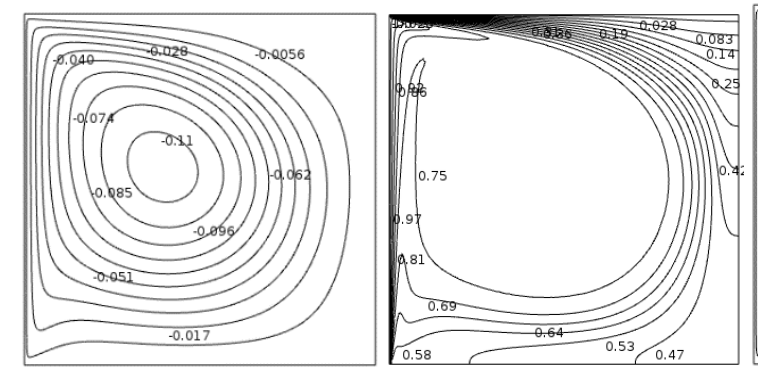

a) $\mathrm{Ri}=0.1 \quad \phi=0.0$

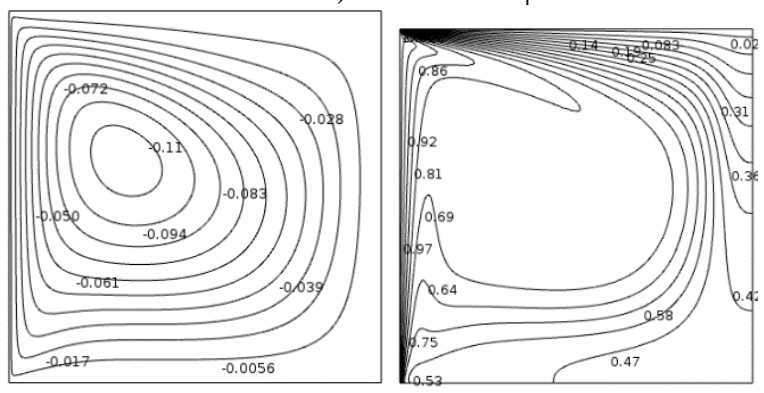

b) $\mathrm{Ri}=1$

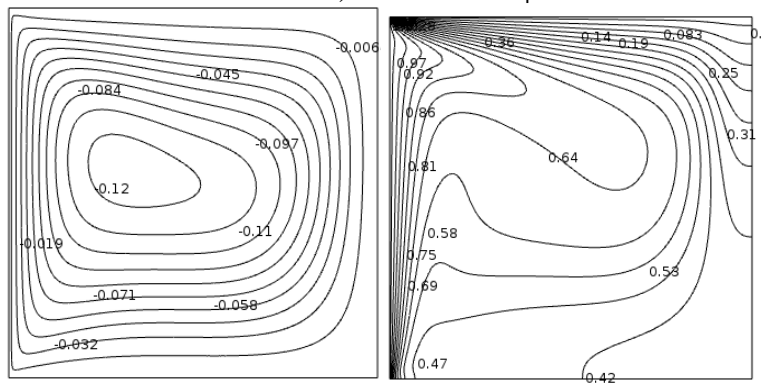

c) $\mathrm{Ri}=10 \quad \phi=0.0$

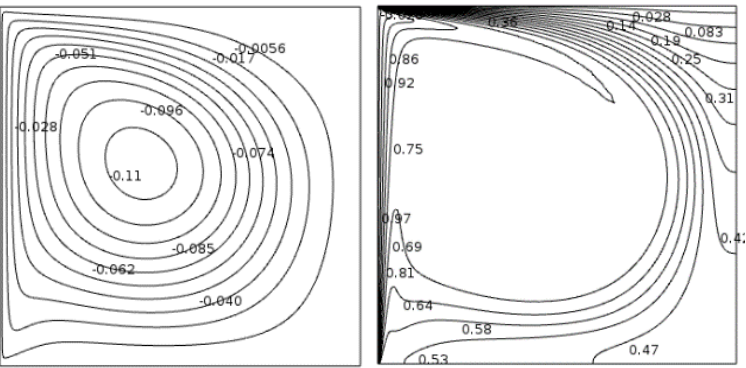

$\phi=0.08$

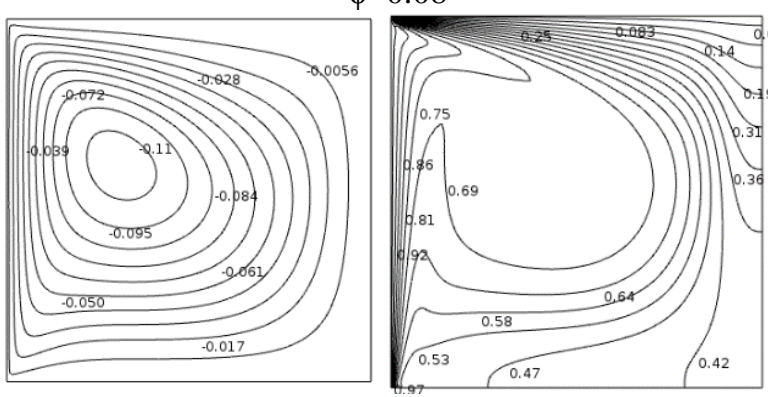

$\phi=0.08$

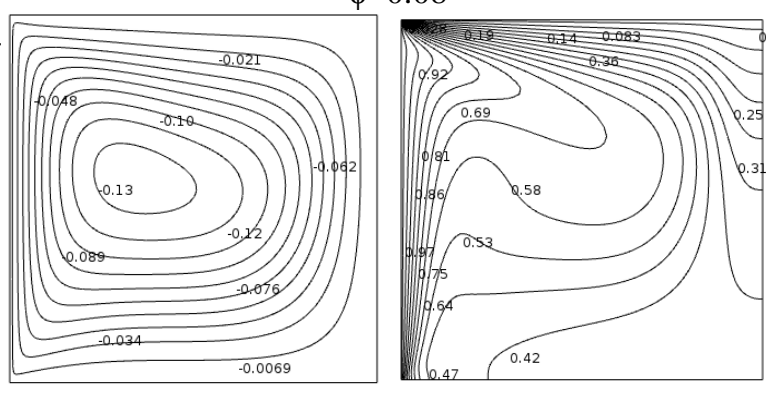

$\phi=0.08$

Fig. 2: Streamlines (on the left) and isotherms (on the right) for 0:100\% EG/W based nanofluid. 

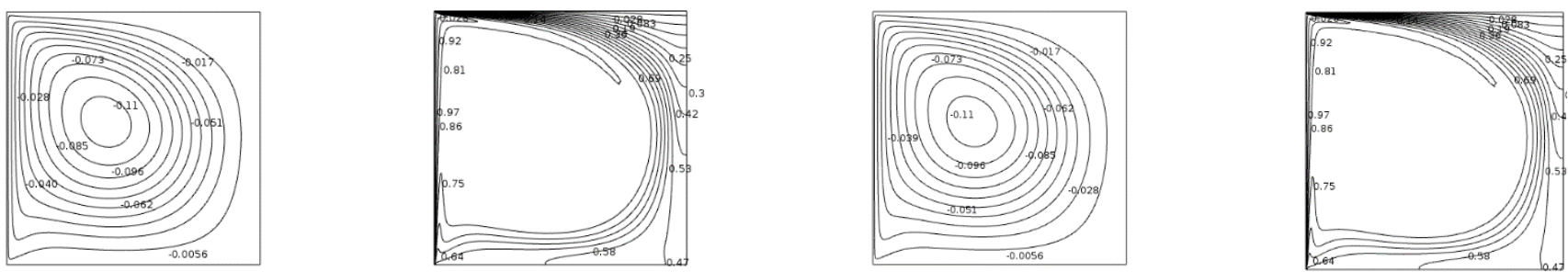

a) $\mathrm{Ri}=0.1 \quad \phi=0.0$
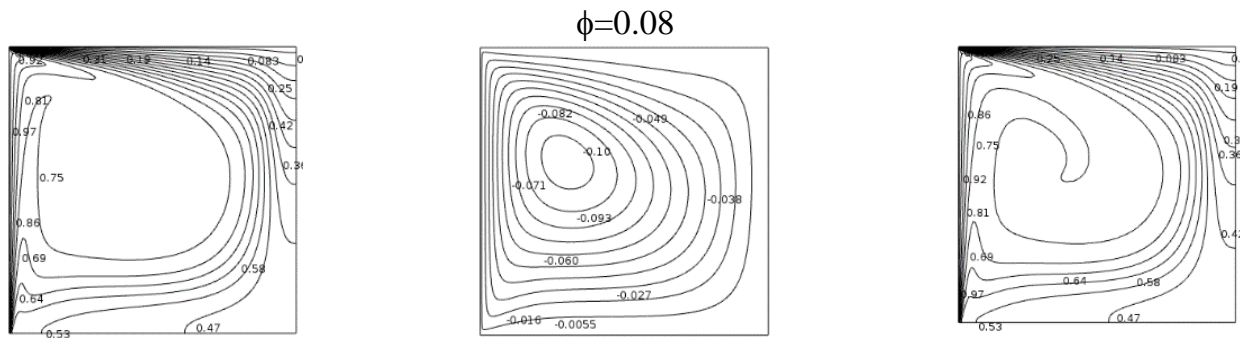

b) $\mathrm{Ri}=1 \quad \phi=0.0$
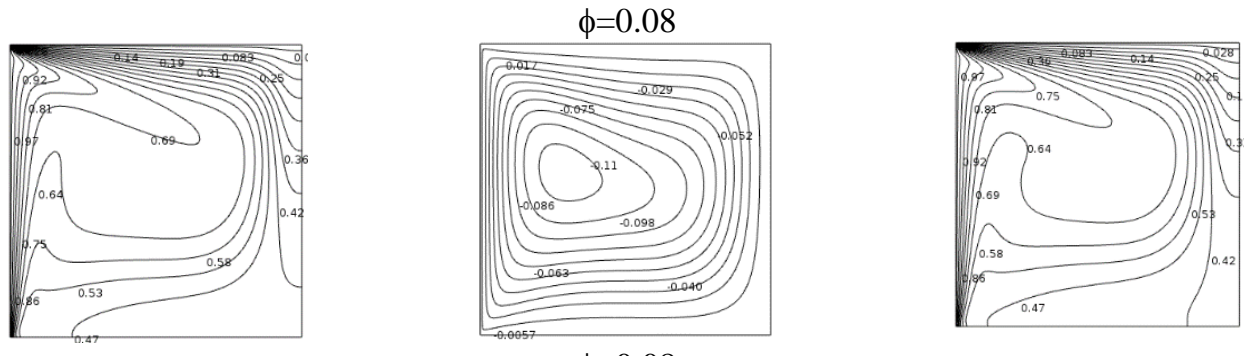

c) $\mathrm{Ri}=10 \quad \phi=0.0$

Fig. 3: Streamlines (on the left) and isotherms (on the right) for 20:80\% EG/W based nanofluid.

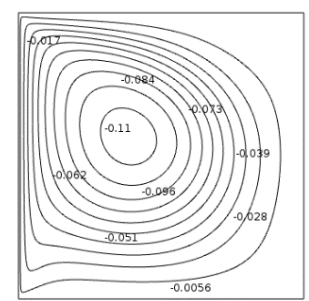

a) $\mathrm{Ri}=0.1 \quad \phi=0.0$

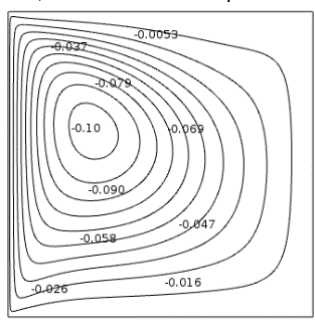

b) $\mathrm{Ri}=1 \quad \phi=0.0$

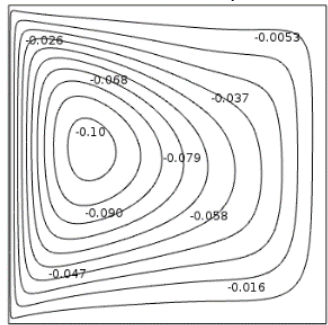

c) $\mathrm{Ri}=10$
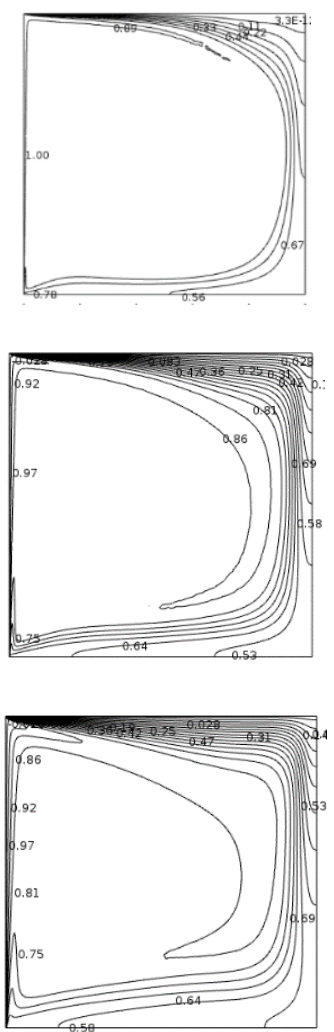

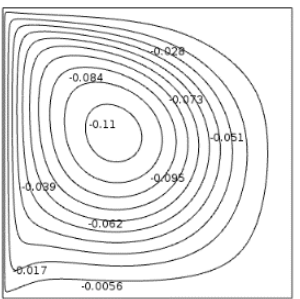

$\phi=0.08$

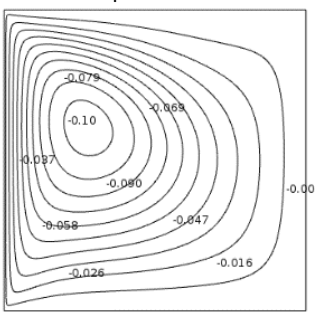

$\phi=0.08$

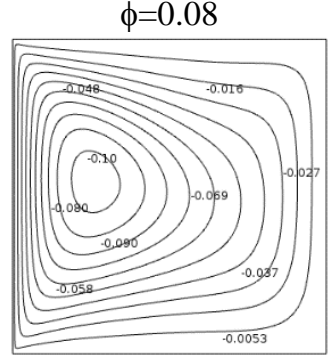

$\phi=0.08$
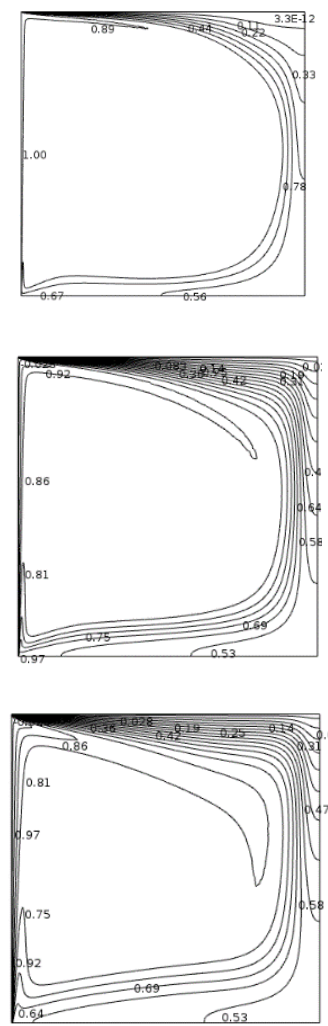

Fig 4: Streamlines (on the left) and isotherms (on the right) for 80:20\% EG/W based nanofluid. 


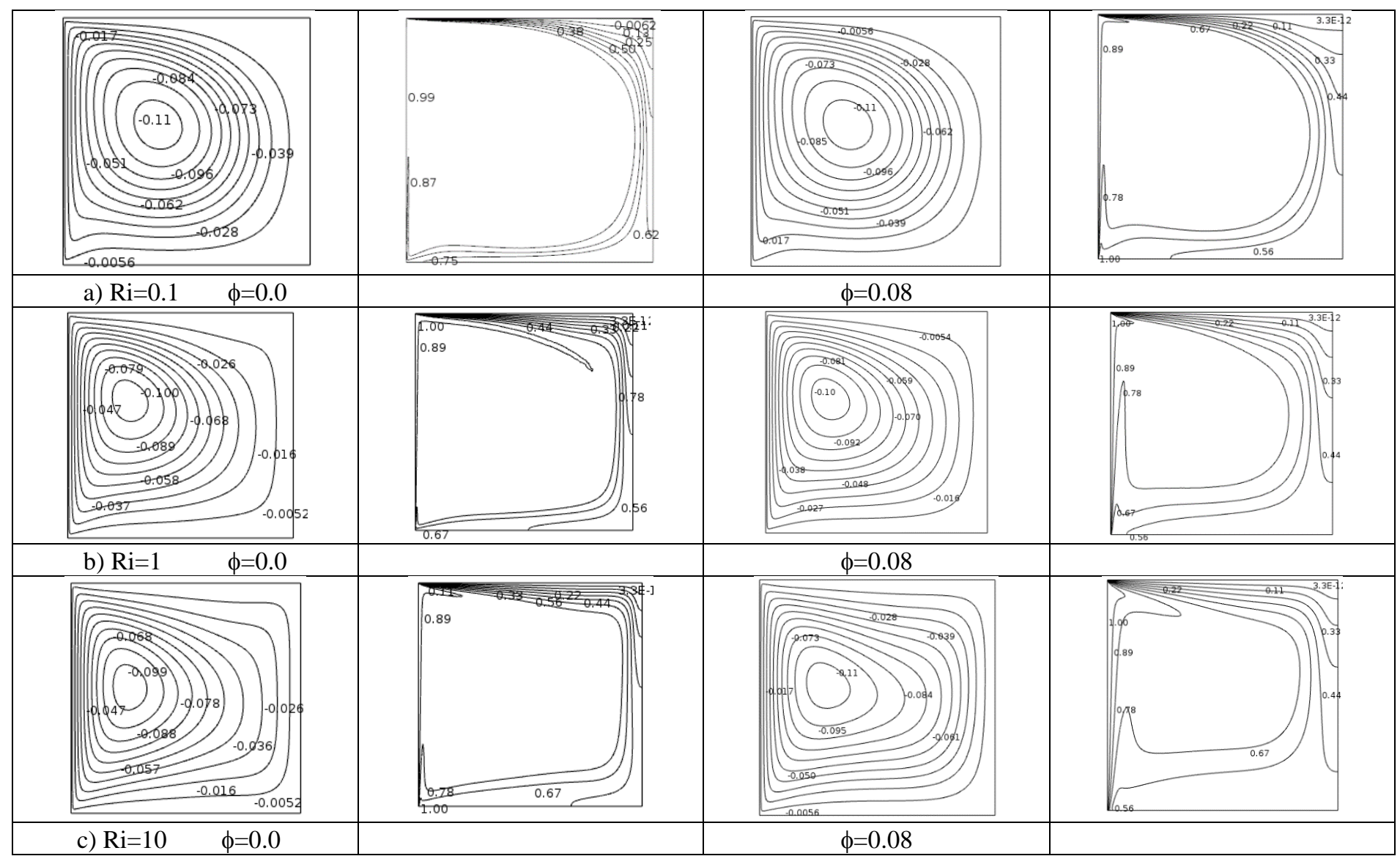

Fig 5: Streamlines (on the left) and isotherms (on the right) for 100:0\% EG/W based nanofluid.

Variation of the average Nusselt is shown in Table 2 for various values of governing parameters. As it can be seen from Table 2, average Nusselt number gets higher values for low values of Richardson number. For low values of Richardson number, shear forces are dominant over buoyancy forces. Fluid particles along the hot wall are carried towards the cold wall by the movement of hot wall in vertical direction. This results in a higher temperature gradient on the hot wall. Therefore, the average Nu number gets higher values. As it can also be observed from Table 2 that solid volume fraction has a significant effect on average Nusselt number and it shows an increase with an increase in the solid particle volume fraction. Average Nusselt number shows a significant increase with an increase in the Prandtl number depending on the increase in the ethylene glycol volume fraction in the base fluid. This is because of the fact that fluid with the highest Prandtl number is capable to carry more heat away from the hot wall in the enclosure.

Table 2: Variation of the average Nusselt number.

\begin{tabular}{|c|c|c|c|c|c|c|c|}
\hline \multirow{2}{*}{$\mathrm{Ri}$} & $\phi$ & $\begin{array}{c}0: 100 \% \\
\text { EG/W }\end{array}$ & $\begin{array}{c}20: 80 \% \\
\text { EG/W }\end{array}$ & $\begin{array}{c}40: 60 \% \\
\text { EG/W }\end{array}$ & $\begin{array}{c}60: 40 \% \\
\text { EG/W }\end{array}$ & $\begin{array}{c}80: 20 \% \\
\text { EG/W }\end{array}$ & $\begin{array}{c}100: 0 \% \\
\text { EG/W }\end{array}$ \\
\hline \multirow{3}{*}{0.1} & 0.00 & 19.3371 & 23.6082 & 29.7085 & 37.2910 & 46.2144 & 54.0521 \\
\cline { 2 - 8 } & 0.04 & 21.3270 & 25.9975 & 32.6552 & 44.8590 & 51.1305 & 60.4953 \\
\cline { 2 - 8 } & 0.08 & 23.4165 & 28.5026 & 35.7271 & 35.7363 & 56.1935 & 67.1378 \\
\hline \multirow{3}{*}{1} & 0.00 & 13.1629 & 15.6100 & 19.0650 & 23.3952 & 28.9696 & 35.1078 \\
\cline { 2 - 8 } & 0.04 & 14.5910 & 17.2690 & 21.0470 & 28.2921 & 31.9085 & 38.7360 \\
\cline { 2 - 8 } & 0.08 & 16.1076 & 19.0227 & 23.1326 & 23.1338 & 34.9842 & 42.5117 \\
\hline \multirow{3}{*}{10} & 0.00 & 10.2467 & 11.6687 & 13.7178 & 16.2759 & 19.5413 & 23.2129 \\
\cline { 2 - 8 } & 0.04 & 11.4495 & 13.0039 & 15.2478 & 19.9530 & 21.6556 & 25.7005 \\
\cline { 2 - 8 } & 0.08 & 12.7410 & 14.4331 & 16.8773 & 16.8777 & 23.8980 & 28.3370 \\
\hline
\end{tabular}




\section{Conclusion}

The present study considers laminar, mixed convection flow of nanofluids in a square enclosure heated from left wall that moves with a constant velocity and cooled from the stationary adjacent top wall. The other walls are stationary and adiabatic. Heat transfer enhancement of ethylene glycol and water mixture based $\mathrm{Al}_{2} \mathrm{O}_{3}$ nanofluids is studied numerically for a range of Richardson numbers, volume fractions, and volume ratios of ethylene glycol to water. The results show that the addition of nanoparticles increase the heat transfer rate. Results also show that heat transfer rate increases with a decrease in Richardson number. Finally, results show that the average Nu number shows a considerable increase with an increase of ethylene glycol volume fraction in the base fluid.

\section{References}

[1] J. A. Eastman, S. U. S. Choi, S. Li, W. Yu, and L. J. Thompson, "Anomalously increased effective thermal conductivities of Ethylene glycol-based nanofluids containing Copper nanoparticles," Appl Phys Lett, vol. 78, pp. 718$720,2001$.

[2] P. Keblinski, S. R. Phillpot, S. U. S Choi, and J. A. Eastman, "Mechanisms of heat flow in suspensions of nano-sized particles (nanofluids)," Int J Heat Mass Transfer, vol. 45, pp. 855-863, 2002.

[3] K. Khanafer, K. Vafai, and M. Lightstone, "Buoyancy-driven heat transfer enhancement in a two-dimensional enclosure utilizing nanofluids," Int J Heat Mass Transfer, vol. 46, pp. 3639-3653, 2003.

[4] R. Y. Jou and S. C. Tzeng, "Numerical research of nature convective heat transfer enhancement filled with nanofluids in rectangular enclosures," Int Commun Heat Mass Transfer, vol. 33, pp. 727-736, 2006.

[5] E. B. Ogut, "Natural convection of water-based nanofluids in an inclined enclosure with a heat source," International Journal of Thermal Sciences, vol. 48, pp. 2063-2073, 2009.

[6] S. M. Vanaki and H. A. Mohammed, "Numerical study of nanofluid forced convection flow in channels using different shaped transverse ribs," Int. Comm. in Heat and Mass Transfer, vol. 67, pp. 176-188, 2015.

[7] R. Nebbatia and M. Kadjab, "Study of forced convection of a nanofluid used as a heat carrier in a microchannel heat sink," Energy Procedia, vol. 74, pp. 633 - 642, 2015.

[8] A. Akbarinia and A. Behzadmehr, "Numerical study of laminar mixed convection of a nanofluid in horizontal curved tubes," Applied Thermal Engineering, vol. 27, pp. 1327-1337, 2007.

[9] K. Kahveci and E. B. Öğ̈̈t, "Mixed convection of water-based nanofluids in a lid-driven square enclosure with a heat source," Heat Transfer Research, vol. 42, pp. 711-735, 2011.

[10] M. Kalteh K. Javaherdeh, and T. Azarbarzin, "Numerical solution of nanofluid mixed convection heat transfer in a liddriven square cavity with a triangular heat source," Powder Technology, vol. 253 pp. 780-788, 2014.

[11] G. H. R. Kefayati, "Mixed convection of non-Newtonian nanofluids flows in a lid-driven enclosure with sinusoidal temperature profile using FDLBM," Powder Technology, vol. 266, pp. 268-281, 2014.

[12] F. Garoosi and F. Hoseininejad, "Numerical study of natural and mixed convection heat transfer between differentially heated cylinders in an adiabatic enclosure filled with nanofluid," Journal of Molecular Liquids, vol. 215, pp. 1-17, 2016.

[13] S. E. Ahmed, M. A. Mansour, A. K. Hussein, and S. Sivasankaran, "Mixed convection from a discrete heat source in enclosures with two adjacent moving walls and filled with micropolar nanofluids," Engineering Science and Technology, an International Journal, vol. 19, pp. 364-376, 2016.

[14] M. H. Hasib, Md. S. Hossen, and S. Saha, "Effect of tilt angle on pure mixed convection flow in trapezoidal cavities filled with water- $\mathrm{Al}_{2} \mathrm{O}_{3}$ nanofluid," Procedia Engineering, vol. 105, pp. 388-397, 2015.

[15] D. Cabaleiro, L. Colla, F. Agresti, L. Lugo, and L. Fedele, "Transport properties and heat transfer coefficients of $\mathrm{ZnO/(ethylene} \mathrm{glycol} \mathrm{+} \mathrm{water)} \mathrm{nanofluids,"} \mathrm{Int.} \mathrm{J.} \mathrm{of} \mathrm{Heat} \mathrm{and} \mathrm{Mass} \mathrm{Transfer,} \mathrm{vol.} \mathrm{89,} \mathrm{pp.} \mathrm{433-443,} 2015$.

[16] S. Z. Heris, M. Shokrgozar, S. Poorpharhang, M. Shanbedi, and S. H. Noie, "Experimental study of heat transfer of a car radiator with CuO/ethylene glycol-water as a coolant," J. Disper. Sci. Technol., vol. 35 pp. 677-684, 2014.

[17] Z. Said, M. H. Sajid, M. A. Alim, R. Saidur, and N. A. Rahim, "Experimental investigation of the thermophysical properties of $\mathrm{Al}_{2} \mathrm{O}_{3}$-nanofluid and its effect on a flat plate solar collector," Int. Commun. Heat Mass, vol. 48 pp. 99 $107,2013$.

[18] H. C. Brinkman, “The viscosity of concentrated suspensions and solutions," J. Chem Phys, vol. 20, pp. 571-581, 1952. 
[19] Y. Xuan and W. Roetzel, "Conceptions for heat transfer correlation of nanofluids," Int J Heat Mass Transfer, vol. 43, pp. 3701-3707, 2000.

[20] W. Yu and S. U. S. Choi, "The role of interfacial layer in the enhanced thermal conductivity of nanofluids: a renovated Maxwell model," J. Nanoparticles Res, vol. 5, pp. 167-171, 2003. 